\title{
Narrativa transmedia y mundos transmediales: Una propuesta metodológica para el análisis de un ecosistema mediático, caso Civil War
}

\section{Transmedia storytelling and transmedial worlds: A methodological proposal for the analysis of a media ecosystem, case Civil War}

\author{
Tomás Atarama-Rojas y Natalie Menacho-Girón ${ }^{1}$ \\ Recibido: 19-09-2017 - Aceptado: 12-12-2017 \\ DOI: https://doi.org/10.26441/RC17.1-2018-A2
}

\begin{abstract}
RESUMEN: La comunicación transmedia ha logrado un importante crecimiento y relevancia en los últimos años y ha sido considerada por productores y organizaciones como una estrategia fundamental en el desarrollo de sus nuevos proyectos, para darlos a conocer a través de una diversidad de medios y plataformas. Al mismo tiempo, este proceso se ha visto influenciado por una cultura participativa conformada por los prosumidores. En el presente trabajo, se busca conocer cómo y qué aporta tal variedad de medios en la construcción de los mundos transmediales. Para ello se plantea como objeto de estudio el ecosistema mediático de Civil War de Marvel; el cómic inició como un crossovery actualmente puede considerarse uno de los casos de narrativa transmedia más completos y complejos en relación a la multiplicidad de medios empleados. Es a partir del análisis de estos nodos que se procura describir las dinámicas que se dan en el mundo transmedial.
\end{abstract}

Palabras clave: narrativa transmedia; Civil War; cómic; Marvel; mundo transmedial; prosumidor.

ABSTRACT: Transmedia communication has achieved an important evolution and relevance in the last years, being considered by producers and organizations as a key strategy in the development of new projects, known through a diversity of media and platforms. At the same time, this process is influenced by a participative culture made up the prosumers. In this paper, we want to know how and what contribution brings the variety of media in the construction of transmedia worlds. Therefor it is planted as object of study the media ecosystem of Marvel's Civil War; the comic began as a crossover and now it can be considered one of the transmedia storytelling more complete and complex cases in relation with the multiplicity of media involved. Is with the analysis of these nodes that we seek to describe the dynamics that take place in the transmedial world.

Keywords: transmedia storytelling; Civil War; comic; Marvel; transmedial world; prosumer.

1 Tomás Atarama-Rojas es Máster en Creación de Guiones Audiovisuales. Es profesor de Fundamentos de Guion, Comunicación Narrativa y Storytelling, e investigador en la Facultad de Comunicación de la Universidad de Piura. tomas.atarama@udep.pe, http://orcid.org/0000-0002-4430-3391

Natalie Menacho-Girón es egresada de la Facultad de Comunicación de la Universidad de Piura. natalie.menacho@gmail.com. 


\section{Introducción}

En los últimos años, el escenario transmedia se ha visto enriquecido por los avances tecnológicos, la convergencia de medios, y el papel que ha adquirido el prosumidor como influenciador en la creación de nuevos productos, dando paso a la aparición de nuevas relaciones y flujos transnacionales (Jenkins, Ford \& Green, 2015), así como nuevas narrativas transmediales (Scolari, 2014). Es en este contexto que las organizaciones se han expuesto a una reconversión industrial y se ven motivadas a apostar por productos con alto potencial transmedia como los cómics, con el auge que han conseguido últimamente y el éxito taquillero de las últimas adaptaciones cinematográficas ${ }^{2}$.

Los cómics pueden ser considerados como punto de partida de universos transmedia, enriquecidos a través de múltiples medios (Bellón, 2012). El cómic Civil War (2006) empezó como un crossover entre diferentes cómics de Marvel. El inicio de su historia está compuesto por acontecimientos ocurridos en publicaciones anteriores, dando origen a la trama central que envuelve el conflicto entre personajes principales y de gran acogida por parte del público. Si bien Civil War solamente cuenta con siete ediciones, con el desarrollo de esta narración ficticia se dio paso a diversos spin off contados desde la perspectiva de otros personajes en sus propias series de cómics. Posteriormente, se han ido desarrollando más productos transmediales en torno al cómic, como videojuegos, fanfiction, juguetes, una película, publicidad y merchandising.

En la presente investigación pretendemos describir y reflexionar acerca de los aportes de los diferentes medios al mundo transmedial, considerado como una realidad basada en las relaciones y con una historia dinámica que se expande. Los nodos ${ }^{3}$, que son las unidades con sentido que conforman este ecosistema mediático, pueden desempeñar diferentes funciones, ya sea como puerta de entrada o como fuente de origen para la creación de otros nodos. Es por ello que llevamos a cabo dos tipos de análisis: el primero, en el que clasificaremos estos elementos según la función que realicen como herramientas transmedia; y el segundo, en el que estudiaremos el nivel de profundidad, vinculación y extensión que se da en la estructura narrativa de los nodos. Estas tres variables del segundo análisis son fundamentales, pues son las que contribuyen a la creación de puntos de contacto para que aumente el interés y gozo del público, generando una experiencia óptima y procurando un

2 Entre las adaptaciones más taquilleras se encuentran: The Avengers (2012) que ocupa el quinto puesto en el ranking mundial con \$1,518.8 millones de recaudación; Avengers: Age of Ultron (2015) que ocupa el séptimo puesto con \$1,405.4 millones y Iron Man 3 (2013) que ocupa el décimo segundo lugar con \$1,215.4 millones.

3 Los nodos según la RAE son los puntos de origen de distintas ramificaciones. En este trabajo consideramos nodo a todas las unidades que conforman el mundo transmedial, que se complementan una con otra para generar una mayor comprensión, enriquecimiento y vinculación emocional con el espectador. 
feedback constructivo acorde a las exigencias de los diferentes tipos de espectador en la actualidad, que eligen qué consumir y producen contenido a través de las redes sociales. Todas estas características formarán un producto transmedia de calidad por la complejidad y buen desarrollo de sus elementos integrantes. Para demostrar nuestra hipótesis analizaremos los diferentes medios de Civil War que han sido lanzados al mercado entre los meses de abril, mayo y junio del año 2016, pero también aquellos relevantes que han sido difundidos años atrás, como el cómic principal y los cómics secundarios publicados a partir del año 2006.

\section{Marco Teórico}

El término transmedia es inicialmente empleado por el músico Stuart Sanders Smith en 1975, cuando creó una composición musical conformada, a su vez, por distintas composiciones, producidas en diversos instrumentos y en diferentes estilos. A esta composición le denominó transmedia music (música transmedia). Posteriormente, Marsha Kinder (1991) introdujo el término transmedia en sus estudios sobre comunicación, empleando transmedia intertextuality (intertextualidad transmedia) para referirse a la relación que se desarrollaba entre diversas plataformas como la televisión, videojuegos, cine y juguetes.

En 1999 el concepto de transmedia storytelling (narrativa transmedia) entraría a debate público, cuando se intentaba comprender el éxito de The Blair Witch Project (1999), una película inde- pendiente que obtuvo gran popularidad (Jenkins, 2006). Años más tarde, este concepto sería desarrollado por Henry Jenkins (2003):

En la forma ideal de la narración transmedia, cada medio hace lo que mejor sabe hacer, de modo que una historia pueda ser introducida en una película, expandida a través de la televisión, novelas o cómics y su mundo podría ser explorado y experimentado a través del juego. Cada entrada a la franquicia ha de ser independiente, de forma que no sea preciso haber visto la película para disfrutar con el videojuego y viceversa. Cualquier producto dado es un punto de acceso a la franquicia como un todo.

Dena (2009) difiere en que los medios sean totalmente independientes unos de otros y afirma que aunque cada uno puede ser considerado una puerta de entrada, siguen manteniendo una conexión cercana.

En los siguientes años, Jenkins coloca su noción como elemento central de la cultura de la convergencia (2006) y reformula su definición como un proceso donde elementos integrantes de una ficción aparecen dispersos a través de múltiples canales de distribución con el propósito de crear una experiencia de entretenimiento unificada y coordinada (2007), haciendo hincapié en que lo ideal sería que cada medio hiciera una contribución específica y valiosa a la totalidad de la ficción.

A deducciones similares han llegado otros autores como Scolari, quien en 2011 señaló que uno de los rasgos 
distintivos de las narrativas transmedia es precisamente la expansión del relato por medio de la incorporación de nuevas situaciones y personajes. Además, nos ofrece una propuesta de elementos constituyentes de una narrativa transmedia como: "animación, avances, apps, audio, camisetas, cartas, CD, cine, cómic, correo, discos, infografías, juegos, libros, mangas, merchandising, teléfonos, muñecos, parques temáticos, radio, realidad virtual, redes sociales, revistas, sellos, postales, teatro, televisión, videojuegos tradicionales y en línea, web cómic, websodios, web tv" (Scolari, 2013, p. 14).

Algunos de estos componentes pueden no contar con una estructura narrativa, pero brindan la información necesaria para moldear el mundo transmedial (Zimmermann, 2015), como los juguetes y figuras de acción fabricados en base a personajes de Star Wars o las cajas de pizza decoradas con los personajes de Civil War; ambos funcionan como puntos de entrada al mundo de ficción y, por lo tanto, ayudan a comprenderlo mejor. La diversidad de estos medios es la razón por la que autores como Carlón (2015) los han considerado como especies que no están aislados unos de otros y que conviven todos en un ecosistema comunicativo. Esta corriente de estudio conocida como ecología de medios es una disciplina nacida en los años 60, desarrollada en un inicio por investigadores como Marshal McLuhan y Neil Postman; actualmente se encuentra aún en proceso de consolidación (Scolari, Aguado \& Feijóo, 2013). Postman en el 2000 planteó que el uso de la palabra "ecología" se refiere al interés no solo en los medios, sino también en cómo la cultura es moldeada por la interacción entre los humanos y los medios.

Esta interacción involucra el consumo y generación de cultura de imágenes e ideas a partir de las cuales la población conforma algunos de sus referentes más significativos (Corona, 2016) y, como audiencia, la lleva a que exponga sus comentarios y teja redes sociales sin importar la distancia física y geográfica (Orozco, 2006).

El público ha sufrido una transformación, ha pasado de ser un espectador a ser un público más activo que interactúa a través de las redes sociales y hace uso de diferentes plataformas y dispositivos. Como el mismo Jenkins (2006) explica, si los viejos consumidores se suponían pasivos, invisibles, aislados y predecibles; los nuevos consumidores son activos, migratorios, ruidosos y muestran una dudosa lealtad a las cadenas, las redes y los medios.

A este nuevo consumidor se le denomina prosumidor; término acuñado en la década de los ochenta por Alvin Toffler para referirse a una tercera etapa económica en la que las personas producen parte de su propio consumo (Lastra, 2016). El prosumidor juega un rol importante como un multiplicador que se encarga de incrementar y participar en el proceso de expansión de los contenidos (Scolari, 2012). Esta producción de contenido, conocido como Contenido Generado por el Usuario o CGU, engloba: 
Todos aquellos formatos de contenido, disponibles a través de redes sociales y plataformas online, creados y distribuidos por uno o varios individuos no profesionales. El resultado final puede ser tanto la invención de una nueva obra como la adaptación de propuestas anteriores, siempre de forma libre y voluntaria. Este tipo de producciones se caracterizan por su alto componente creativo, por lo general son de carácter transmedia y fruto de dinámicas colaborativas en la web (Fernández, 2013, p.60).

En las narrativas transmedia cada historia aspira a una elaboración moldeada por decisiones surgidas tanto de las salas de reuniones corporativas como por decisiones nacidas en dormitorios de adolescentes (Jenkins, 2010). Para Rodríguez (2012), el contenido de las narrativas transmedia "nace y evoluciona inseminado ya en múltiples soportes y plataformas, alimentado por creadores profesionales y por fans amateurs, en ocasiones extraordinariamente activos y competentes" (p. 66).

Por otro lado, si bien es importante que los creadores de contenidos presten atención a la voluntad del público, esto no implica que estos influenciadores sean más apropiados y efectivos que los profesionales para gestionar la circulación de contenido. El profesional debe crear contenidos que sean profundizables y que generen complejidad para garantizar el interés y compromiso con sus fans y con los públicos indirectos que posteriormente ayudarán a la circulación de estos textos narrativos (Jenkins et al., 2015). Asimismo, los profesionales deben saber gestionar y sacar provecho del potencial que brinda la tecnología en el entorno digital (Tur-Viñes \& Rodriguez, 2014).

Conociendo mejor los aspectos relacionados a las narrativas transmedia, es importante mencionar dos más que son relevantes. El primero es que un relato debe ser considerado transmedia en base a las funciones que cumple. Esto implica reconocer que los relatos y narrativas posean más de un significado, según el momento o fase de desarrollo, por lo que se propone preguntar cuándo es transmedia, en lugar de qué es transmedia (Corona, 2016). El segundo aspecto es el que menciona Rosendo (2016), quien señala que dentro del mundo de la narrativa transmedia nos encontramos propuestas que se ocupan de dar otro enfoque a esta realidad. Así tenemos a Klastrup y Tosca (2004, 2014) con el concepto de mundo transmedial que definen como una "imagen mental" compartida, no determinada por su representación concreta en algún medio. Además, lo diferencian del concepto de narrativa transmedia de Jenkins, al centrarse en el estudio de las propiedades abstractas que atraviesan las diferentes manifestaciones en este mundo, en lugar de la narrativa de una historia a través de diversos medios.

Otra propuesta son los mundos imaginarios transmediales de Wolf (2012), conformados por diferentes infraestructuras, en las que encontramos desde la narrativa hasta diversas presentaciones de contenido como mapas, cronologías, genealogías, entre otras, que son acompañadas de elementos 
como imágenes y sonidos. Wolf nos plantea que la creación de estos mundos va más allá del simple relato y se extiende a distintos medios a través de dos procesos: adaptación y crecimiento. En el primero, no se agrega material nuevo, solo se adapta la historia inicial a otro medio; en el segundo, se utiliza un medio distinto al original para aportar material inédito. Indica que en ambos procesos el elemento narrativo puede o no estar conexo; también considera que todos los medios que conforman este mundo imaginario funcionan como ventanas y a mayor número de ventanas, más independiente será el mundo de un medio en particular.

Ryan (2014) nos trae una tercera propuesta con los mundos narrativos transmediales, en los que plantea como eje de convergencia el elemento narrativo. En este mundo concurren diversos medios que representan distintos aspectos de él y contribuyen a la construcción mental del mismo; por lo que para Ryan es importante establecer una diferencia entre los medios con base en el lenguaje y los audiovisuales.

En esta investigación se empleará el término mundo transmedial, porque se considera que engloba todos los puntos de contacto de la narrativa transmedia (no solo el elemento narrativo) y realza la importancia de las interacciones de los nodos como base de su desarrollo.

Un producto transmedia se desarro- lla en un mundo que puede o no empezar con una estructura narrativa ${ }^{4}$, pero que necesita de esta para expandirse. El producto transmedia se consolida a través de diversos medios que se diferencian uno de otro para ser una entrada independiente para el prosumidor, el cual interactúa con el mundo transmedial y cumple con el rol de difusor y creador de más contenido.

\section{Material y Metodología}

\subsection{Material}

Teniendo en cuenta que buscamos comprobar el enriquecimiento que genera el uso variado y múltiple de medios a las dinámicas del mundo transmedial, en el presente artículo analizaremos los elementos integrantes del ecosistema mediático de Civil War, para conocer qué y cómo aportan cada uno de ellos a la estructura y organización de la narrativa y a la interacción con el prosumidor. Este mundo transmedial tiene como nodos principales al cómic de Marvel, que lleva el mismo nombre y representa un crossover de diferentes publicaciones suyas, y a la película de su universo cinematográfico llamada Captain America: Civil War (2016); ambos son el punto de referencia de otros nodos.

A continuación, detallamos los nodos que conforman el mundo transmedial en sus diferentes presentaciones y

4 Hello Kitty inició en 1974 como un producto decorativo para niñas; actualmente encontramos todo tipo de artículos, ropa, juguetes e incluso una serie animada. En la página oficial de la marca Sanrio vemos que se ha creado una historia y otros personajes en torno a su mundo. 
plataformas, algunos de ellos cuentan con un desarrollo narrativo más elaborado que otros:

\section{Cómics:}

Marvel en su página oficial nos presenta los siguientes cómics relacionados a la trama de Civil War:

- Cómic Civil War: como trama central consta de 7 números. Escrito por el guionista Mark Millar, dibujado por Steven McNiven y publicado a partir de julio del 2006. La historia inicia con un desastre originado en la ciudad de Stanford (Connecticut), tras la batalla entre un grupo de jóvenes superhéroes y unos supervillanos, que ocasiona la muerte de cientos de personas; esto provoca la indignación de la gente y el gobierno propone el Acta de Registro de Superhumanos. A favor del Acta se encuentra Iron Man y en contra tenemos a Captain America; el conflicto entre ambos personajes traerá luchas, enemistades y consecuencias para la mayoría de personajes de Marvel.

- Cómics relacionados: historias tangenciales a la principal, contadas en las series de cómics de otros personajes. Civil War Front Line, New Avengers, The Amazing Spiderman, Wolverine, Fantastic Four, X-men, Ms. Marvel, Black Panther, X Factor, Heroes for Hire, She- Hulk,
Thunderbolts, Young Avengers and Runaways, Punisher: War Journal, Cable and Deadpool.

- Cómics - Números especiales: Civil War: Casualties of War, Civil War: War Crimes, Civil War: The Return, Civil War: Choosing sides.

- Avengers Assamble (Los Vengadores Unidos): parte de la trama original de Civil War es adaptada a cuatro ediciones de este cómic.

\section{Cine:}

- Película Captain America: Civil War: dirigida por Joe y Anthony Russo, fue estrenada en Estados Unidos el 6 de mayo del 2016. Es la secuela de Captain America: The Winter Soldier (2014) y es la que da inicio a la fase 3 del Universo Cinematográfico de Marvel $^{5}$. En el largometraje se ven enfrentados los mismos personajes principales que en el cómic: Captain America e Iron Man, con la diferencia de que en esta ocasión hay una menor intervención de personajes. Aunque se plantea la disputa entre apoyar o rechazar el Acta de Registro de Superhumanos, esta vez los conflictos que surgirán a raíz de esto son diferentes a los del cómic.

- Tráileres: se hicieron dos en los que se muestran diferentes vistazos de la película. Cabe mencionar que la batalla entre Captain America e Iron

5 Marvel hasta el momento ha confirmado tres fases que conforman su universo cinematográfico (MCU: Marvel Cinematic Universe). La primera fase inicia con Iron Man (2008) y termina con The Avengers (2012); la segunda comienza con Iron Man 3 (2013) y culmina con Ant Man (2015) y la tercera fase empieza con Captain America: Civil War (2016) y finaliza con Avengers Infinity War - Part 2 (2019). 
Man y la aparición del personaje Spiderman, mostrados en los tráileres, causaron mucha expectativa en el público.

\section{Televisión:}

- Live shows:

- Jimmy Kimmel Live: el elenco de la película Captain America: Civil War realiza entrevistas y dan a conocer el póster y el primer tráiler de la película.

- The Tonight Show Starring Jimmy Fallon: el elenco participa de juegos y hacen sketches junto al conductor.

- Spots de la película: se hicieron un total de 63, además del emitido durante el Super Bowl.

\section{Juegos:}

- Marvel Future Fight: es un juego móvil cuya trama inicia con una advertencia del futuro sobre el colapso de las dimensiones del multiverso, con lo que queda en manos del usuario asegurar la supervivencia de la humanidad luchando a través de diferentes niveles con un equipo conformado por tres personajes del universo Marvel. El juego permite modificar la vestimenta de los personajes por una con los diseños vistos en la película Captain America: Civil War.

- Marvel Contest of Champions: juego móvil en el que se forma un súper equipo con diferentes personajes de Marvel, ya sean superhéroes o supervillanos para posteriormente enfrentarlos. Este juego presenta contenido especial sobre Civil War y da la posibilidad de enfrentar a Captain America y Iron Man.

- Marvel Puzzle Quest: es un juego móvil de estrategia en el que se conecta fichas y se va desbloqueando personajes y habilidades; también se puede elegir a los integrantes de un equipo y entablar batallas con otros grupos. En este juego encontramos una referencia a Civil War al darle la posibilidad al usuario de escoger entre el equipo de Captain America o el equipo de Iron Man.

- Marvel Avengers Academy: juego móvil en el que se presenta una versión joven de los superhéroes que conforman a los Vengadores; en este juego los personajes pertenecen a una academia donde son entrenados y desarrollan sus habilidades para lidiar contra los enemigos.

- Marvel Avengers Alliance 2: es un juego móvil en el que se puede crear alianzas con amigos y otros jugadores del planeta para enfrentar adversarios letales y prevalecer. Este juego, al igual que los anteriores, brinda contenido relacionado al evento Civil War.

- Marvel Heroes 2016: es un juego gratuito en línea para múltiples jugadores, creado por David Brevik. Marvel Heroes combina el estilo central del juego de RPG de acción y MMO (masivo en línea para múltiples jugadores) con la expansiva biblioteca de héroes del Universo Marvel. En el juego, los usuarios pueden coleccionar y jugar como sus personajes favoritos. 


\section{Eventos:}

- Disney's D23 expo: en el evento se presentó la película al público asistente y a parte del elenco.

- Avant Premieres: el elenco de Captain America: Civil War acudió a los estrenos de la película en Londres, Berlín, Singapur, Beijing y París.

- World Premiere: se llevó acabo en Los Ángeles y asistieron tanto los productores, el elenco, como personalidades invitadas.

\section{Publicidad:}

- Synchrony Bank: elaboraron cuatro spots que inician con el tráiler de la película y luego presentan cuatro situaciones problemáticas que son resueltas por los protagonistas con ciertas dificultades. Su slogan es: "Saving the world is hard, saving with synchrony bank is easy"

- Pizza Hut: relacionó su promoción de 'cinco dólares más' para la elección de cualquier sabor y elaboró cajas de pizza con diseños alusivos a la película.

- Audi: promocionan su último modelo haciendo un spot que se desarrolla en el contexto de la película.

- Mouser Innovation Lab: en conjunto con Marvel trae a la vida real la tecnología vista en Captain America: Civil War, a través de la elaboración de equipos lo más realistas y similares a los empleados por los héroes.

\section{Juguetes/Productos:}

- Funko: ha producido una línea de figuras relacionada a la película y también tiene las figuras clásicas de los personajes.
- Tsum Tsum: tiene una línea de almohadas caracterizadas como los personajes de Civil War.

- LEgO Marvel Super Heroes: Lego ha sacado sets relacionados a escenas de la película.

- Hasbro Marvel Super Hero Mashers: Hasbro lanza una línea de juguetes de los personajes que se pueden armar y desarmar para formar nuevas combinaciones.

- Wallmart: tiene una línea de productos para el hogar con diseños de la película y el cómic.

Redes sociales: contenido variado ha sido compartido en las cuentas oficiales de Marvel, en Facebook, Twitter, YouTube, Tumblr e Instagram.

Sitio Web: toda la información sobre Civil War se brinda en la página oficial de Marvel (marvel.com). Para la película se creó una sección especial (marvel. com/captainamerica) donde se brinda información de los equipos, los personajes, el elenco, etc.

App: la aplicación Marvel Unlimited permite descargar los cómics de Civil War.

Fanmade: los fans de esta historia han realizado todo tipo de contenidos que involucran memes, ilustraciones, videos, fanmade trailers, mashup, parodias, etc.

\subsection{Metodología}

Con el fin de conocer el aporte que hace la diversidad de nodos a las narrativas transmedia y a la construcción del 
mundo transmedial, en el siguiente trabajo hemos realizado dos análisis del ecosistema mediático que conforma el mundo transmedial de Civil War. Para esto, se ha tenido en cuenta un periodo de análisis comprendido entre los meses de abril y junio del 2016, pues la película, que es uno de los nodos principales, fue estrenada en el mes de mayo, y se ha considerado un mes antes y después para estudiar los diversos medios elaborados para la promoción y publicidad del filme, como tráileres, eventos, merchandising, juguetes, entre otros. Sin embargo, algunos de los elementos analizados pertenecen a un periodo de tiempo anterior como son el cómic central, también valorado como nodo principal, y los cómics tangenciales, ambos publicados a partir del año 2006. Se ha visto necesario estudiarlos porque han sido la base para la creación de los otros nodos.

El primer análisis está basado en la propuesta de Robledo, Atarama, y Palomino (2017); Scolari (2009) y Askwith (2007) sobre las herramientas transmediales. Con la ficha de estudio, se valora el ecosistema mediático en función a la contribución de cada nodo como herramienta para la construcción del mundo transmedial. A continuación, presentamos un cuadro en el que se aprecian las diferentes herramientas transmediales y su definición correspondiente:

Tabla 1. Unidades de análisis según su valor como herramientas transmediales

\begin{tabular}{|l|l|}
\hline Herramienta transmedia & \multicolumn{1}{c|}{ Definición } \\
\hline Macrohistoria & \multicolumn{1}{|c|}{ Contenido expandido } \\
\hline \multicolumn{2}{|c|}{ Información relevante: información que amplía el saber específico del relato global. } \\
\hline Historias paralelas & $\begin{array}{l}\text { Relatos que se desarrollan al mismo tiempo que la historia } \\
\text { principal. }\end{array}$ \\
\hline Historias previas & Relatos que se desarrollan antes que la historia principal. \\
\hline Historias póstumas & Relatos que se desarrollan posteriormente a la historia principal. \\
\hline Historias intersticiales & $\begin{array}{l}\text { Relatos que se desarrollan entre dos nodos que obedecen a una } \\
\text { secuencia (tienen como finalidad mantener el interés). }\end{array}$ \\
\hline Historias periféricas & Relatos que poseen una ligera relación con la historia principal. \\
\hline Información extratextual: información referente a cuestiones que no se perciben en el relato \\
global, pero que le pertenecen.
\end{tabular}




\begin{tabular}{|c|c|}
\hline \multicolumn{2}{|c|}{ Interacción social: foros sociales que permiten la interacción entre el público. } \\
\hline Interacción social & Participación de los fans sobre todo en Internet. \\
\hline \multicolumn{2}{|c|}{ Interactividad: intercambio recíproco de los creadores del relato con el público. } \\
\hline $\begin{array}{l}\text { Contribuciones } \\
\text { reconocidas }\end{array}$ & $\begin{array}{l}\text { Ocasiones planificadas en la que los usuarios realizan una } \\
\text { contribución reconocida que no altera la trama. }\end{array}$ \\
\hline Interacciones influyentes & $\begin{array}{l}\text { Contribuciones de los usuarios que sí pueden determinar } \\
\text { cambios. }\end{array}$ \\
\hline \multicolumn{2}{|c|}{$\begin{array}{l}\text { Contenido generado por el usuario: diversidad de producciones que el seguidor del relato } \\
\text { realiza en torno a este. }\end{array}$} \\
\hline $\begin{array}{l}\text { Plataformas de } \\
\text { conocimiento }\end{array}$ & $\begin{array}{l}\text { Plataformas en el que el usuario puede adquirir y compartir } \\
\text { información. }\end{array}$ \\
\hline $\begin{array}{l}\text { Plataformas de opinión y } \\
\text { expresión }\end{array}$ & $\begin{array}{l}\text { Plataformas en el que el usuario puede expresarse y compartir } \\
\text { opiniones con otros. }\end{array}$ \\
\hline Trabajos creativos & Contenido diverso elaborado por el usuario sobre el relato. \\
\hline Juegos interactivos & $\begin{array}{l}\text { Contenido creado por el usuario dentro de los juegos } \\
\text { relacionados al relato. }\end{array}$ \\
\hline \multicolumn{2}{|r|}{ Productos } \\
\hline Merchandising & $\begin{array}{l}\text { Productos relacionados a la historia, elaborados por los mismos } \\
\text { creadores del relato o asociados. }\end{array}$ \\
\hline \multicolumn{2}{|r|}{ Otras actividades } \\
\hline Actividades diversas & $\begin{array}{l}\text { Actividades temáticas o experienciales en relación con el relato } \\
\text { global. }\end{array}$ \\
\hline
\end{tabular}

Fuente: Elaboración propia a partir de Robledo, Atarama, y Palomino (2017), Scolari (2009) y Askwith (2007).

Para este primer análisis, se evaluó el contenido y la plataforma-medio en la cual se difundían las unidades presentadas en el apartado de materiales, con el fin de catalogarlas según el tipo de herramienta que son. La primera herramienta denominada macrohistoria se refiere a la historia principal, considerada la base narrativa del proyecto transmedia (Scolari, 2009; Belsunces, 2011), que puede ser distribuida a través de diferentes medios, plataformas y modelos de negocio creando oportunidades de acceso (TurViñes \& Rodriguez, 2014); a su vez el relato principal también puede ser extendido en cuanto a su contenido. Esta nueva información puede ser catalogada como relevante o extratextual. La información relevante comprende todo aquel contenido que amplifique el saber específico del relato global con el propósito de lograr una mayor comprensión, dentro del cual encontramos: las historias paralelas, que se desarrollan al mismo tiempo que la historia principal; las historias previas o póstumas al relato original; las historias periféricas, que poseen una ligera relación con la historia central, y las historias intersticiales o intermedias. La información extratextual es la que no se observa directamente en el relato global pero guarda relación con este. 
Además de ser expandido, el contenido principal también puede ser adaptado en productos que ofrecen un valor añadido por su utilidad o atractivo para el espectador ocasional, y que sirven para reavivar el interés del fan (Rodríguez et al., 2014).

Así, encontramos las adaptaciones póstumas al contenido original, las promociones que están desligadas temporalmente a este pero que le dan visibilidad por diferentes canales, y los avances, que presentan fragmentos del contenido principal al que se tendrá acceso y que le dan una idea al público de lo que puede esperar.

Dentro de las herramientas transmediales también tenemos la interacción social en la que se analiza la participación de los fans sobre todo en Internet, en foros sociales oficiales que permiten la interacción entre ellos (Askwith, 2007).

Con la herramienta denominada interactividad se habla de la interacción que se da entre los creadores del relato y el público, que puede ser con contribuciones reconocidas, ocasiones planificadas en las que los usuarios realizan un aporte que no altera la trama, o interacciones influyentes, que sí pueden determinar cambios.

Las herramientas relacionadas al Contenido Generado por el Usuario (CGU) son una alternativa de difusión de la narrativa y contribuyen a darle continuidad. En productos está incluido el merchandising relacionado a la historia y elaborado por los mismos creadores del relato o empresas aso- ciadas. Y finalmente, dentro de esta clasificación de herramientas transmediales, se incluyen las actividades temáticas o experienciales relacionadas con el relato global. Todas estas herramientas nos permitirán entender cómo se compone el mundo transmedial a través de diferentes medios, además de conocer qué aporta cada uno.

El segundo análisis explora la estructura narrativa del mundo transmedial de Civil War, en el que se mide el nivel de desarrollo narrativo de cada historia que contribuye a enriquecer el mundo ficticio, por lo que solo se han escogido los nodos que cuentan con una estructura narrativa. Se han establecido dos nodos principales como ejes del análisis: el cómic Civil War y la película Captain America: Civil War; ambos han sido base para la elaboración de otros nodos. Asimismo, se han diseñado tres variables para medir el desarrollo narrativo y su aporte al mundo transmedial.

La primera variable es la profundidad que desarrolla cada narrativa, lo que implica un mayor o menor número de personajes, situaciones, contextos y otros componentes dentro de la historia. En esta variable, se estudiará el nivel de desarrollo que se ha logrado en los personajes, tanto en la cantidad y la diversidad que se pueda apreciar en el relato, como en la función y rol que desempeñan, ya sea como protagonistas o como personajes secundarios; también se evaluará el desarrollo alcanzado en las historias detrás de cada uno 
de ellos, como en los conflictos ${ }^{6}$ y subtramas en los que se ven envueltos. Por esto, podemos decir que habrá un mayor nivel de profundidad si el relato cuenta con un mayor número de personajes desarrollados, que cumplen funciones y roles relevantes dentro de la trama y que, además, se desenvuelven en situaciones complejas que aportan un significado a la historia.

Una segunda variable es la vinculación entre los elementos narrativos de los nodos principales y los secundarios, lo que significa que una historia estará más asociada a otra por el empleo de los mismos personajes y conflictos como sucede entre el cómic principal y los cómics tangenciales, donde se aprecian los mismos personajes involucrados en los mismos eventos, pero contados desde su propia perspectiva en sus historietas correspondientes. Así, podemos deducir que habrá una mayor vinculación si en el relato aparece la mayor cantidad de personajes presentados en los nodos principales y envueltos en situaciones relacionadas al conflicto principal. Si los personajes y los conflictos presentados en el relato no guardan mucha relación con la historia principal entonces habrá un menor nivel de vinculación.

La tercera variable es la extensión de contenido que aportan las narrativas secundarias al relato original. Lo que implica que habrá un mayor nivel de extensión si en los relatos secundarios se presentan nuevos personajes que no han estado involucrados directamente en la trama central de Civil War pero que pueden desempeñar un rol nuevo, propio del relato secundario. A esto se le suma que las situaciones y conflictos desarrollados reflejen una nueva perspectiva fuera de la trama principal.

Se ha optado por estas tres variables porque la narrativa transmedia supone ir creando puntos de reconocimiento, de relación y de contacto para que sea identificable y aumente el gozo del público cuando se conecte con cada uno de estos nodos, y también cuando se expanda el alcance del relato.

Para tener una evaluación más detallada, en cada variable se estudiaron tres categorías cuyos resultados posteriormente han sido promediados; así tenemos las categorías personajes, conflictos y subtramas, por considerarse elementos fundamentales en una narración, además de característicos en los nodos narrativos de Civil War. Finalmente, a cada categoría se le asignó una calificación numérica del "0" al "10" teniendo en cuenta los niveles de profundidad, vinculación y extensión que desarrollan dentro de cada relato, donde el " 0 " representa un valor nulo y "10" es el mayor índice de intensidad. Así, teniendo como nodo referencial al cómic principal, podemos observar que en cuanto a profundidad, los cómics

6 Con conflicto nos referimos tanto a los obstáculos que atraviesan los protagonistas y que forman parte de la trama principal como aquellos conflictos de las subtramas vinculados al objetivo principal; ambos alimentan el desarrollo de la tensión dramática de la historia. 
tangenciales tienen un mayor puntaje, pues sus personajes, conflictos y subtramas cuentan con un nivel de desarrollo considerable; en cambio, el comercial de Audi mantiene un nivel muy bajo pues su desarrollo narrativo es escaso y no aporta al cómic principal. En cuanto a vinculación, los cómics tangenciales también guardan una mayor relación al relato original, a diferencia de la película que, al ser una adaptación, presenta variaciones en los conflictos y subtramas, y un menor número de personajes. Y en cuanto a la variable extensión, las ediciones de $X$-men vinculadas a Civil War tienen un alto puntaje porque aportan personajes, conflictos y subtramas que no han sido cubiertos en el relato original y lo expanden.

Teniendo estos criterios en cuenta, podremos obtener una panorámica donde se pueda esquematizar esta relación del mundo transmedial con los no- dos principales.

Ambos análisis representan un aporte pues hasta el momento no se han desarrollado trabajos que valoren de forma específica la construcción de los mundos transmediales y cómo todos los puntos de acceso finalmente se vinculan con los nodos principales.

\section{Resultados y Reflexión}

Después de haber realizado los análisis, hemos obtenido los siguientes resultados. A continuación, presentamos tres tablas: en la primera, todas las unidades de análisis clasificadas según su valor como herramientas transmediales; en la segunda y tercera se presentan diferentes unidades con desarrollo narrativo evaluadas según su profundidad, vinculación y extensión con respecto a los nodos principales del ecosistema mediático de Civil War: el cómic y la película.

Tabla 2. Análisis de los nodos según su valor como herramientas transmediales

\begin{tabular}{|l|l|}
\hline \multicolumn{1}{|c|}{ Herramienta } & \multicolumn{1}{c|}{ Medio/plataforma/formato } \\
\hline \multicolumn{2}{|c|}{ Contenido principal } \\
\hline $\begin{array}{l}\text { Macrohistoria difundida } \\
\text { tradicionalmente, vía web o vía } \\
\text { móvil }\end{array}$ & Cómic Civil War \\
\hline \multicolumn{1}{|c|}{ Contenido expandido } \\
\hline & \multicolumn{1}{|c|}{ Información relevante } \\
\hline Historias paralelas & $\begin{array}{l}\text { Cómics: Civil War Front Line, New Avengers, The Amazing } \\
\text { Spiderman, Wolverine, Fantastic Four, X-men, Ms. Marvel, } \\
\text { Black Panther, X Factor, Heroes for Hire, She- Hulk, } \\
\text { Thunderbolts, Young Avengers and Runaways, Punisher: } \\
\text { War Journal, Cable and Deadpool. } \\
\text { Cómics Números especiales: Civil War: Casualties of War, } \\
\text { Civil War: War Crimes, Civil War: The Return, Civil War: } \\
\text { Choosing sides. }\end{array}$ \\
\hline Historias previas & $\begin{array}{l}\text { Cómics: The New Avengers, The Amazing Spiderman, } \\
\text { Fantastic Four. }\end{array}$ \\
\hline
\end{tabular}




\begin{tabular}{|c|c|}
\hline Historias póstumas & $\begin{array}{l}\text { Película Captain America: Civil War. } \\
\text { Cómic: Captain America, Civil War: Fallen Son - The Death of } \\
\text { Captain America, The Initiative. }\end{array}$ \\
\hline Historias intersticiales & $\begin{array}{l}\text { Página oficial de Marvel (Marvel.com) y sus cuentas en redes } \\
\text { sociales: Facebook, YouTube, Twitter, Tumblr e Instagram. } \\
\text { Cómics Números especiales: Civil War: Casualties of War, } \\
\text { Civil War: War Crimes, Civil War: The Return, Civil War: } \\
\text { Choosing sides. }\end{array}$ \\
\hline Historias periféricas & $\begin{array}{l}\text { Cómics: Amazing Spiderman, Wolverine, Fantastic Four, New } \\
\text { Avengers Young Avengers and Runaways, Heroes for Hire, } \\
\text { Ms. Marvel, Cable and Deadpool, etc. }\end{array}$ \\
\hline \multicolumn{2}{|r|}{ Información extratextual } \\
\hline Información extratextual & $\begin{array}{l}\text { Información sobre los personajes, los cómics, la película y } \\
\text { más en la página oficial de Marvel y sus redes sociales. } \\
\text { Eventos: Disney's D23. }\end{array}$ \\
\hline \multicolumn{2}{|r|}{ Contenido adaptado } \\
\hline Adaptaciones póstumas & Película Captain America: Civil War. \\
\hline Promociones & $\begin{array}{l}\text { Dos tráileres de la película y spots, adelantos televisivos. TV } \\
\text { shows: Jimmy Kimmel, Jimmy Fallon. } \\
\text { Alianzas promocionales: Audi, Pizza Hut, Synchrony Bank, } \\
\text { Mouser Innovation Lab. }\end{array}$ \\
\hline Avances & Dos tráileres de la película y spots/adelantos televisivos. \\
\hline \multicolumn{2}{|r|}{ Interacción social } \\
\hline Interacción social & $\begin{array}{l}\text { Página oficial de Marvel y sus cuentas en Twitter, Facebook, } \\
\text { YouTube, Instagram y la aplicación: Marvel Unlimited app. } \\
\text { Redes sociales de los directores y productores de la película, } \\
\text { así como las de los actores. Disney's D23. }\end{array}$ \\
\hline \multicolumn{2}{|r|}{ Interactividad } \\
\hline Contribuciones reconocidas & $\begin{array}{l}\text { Trivias y concursos en la página web de Marvel. Redes } \\
\text { sociales de los directores y productores de la película, así } \\
\text { como las de los actores. }\end{array}$ \\
\hline Interacciones influyentes & $\begin{array}{l}\text { Videoblogs de los creadores e ilustradores de los cómics, } \\
\text { directores y actores de la película. } \\
\text { Artes conceptuales. }\end{array}$ \\
\hline \multicolumn{2}{|r|}{ Contenido generado por el usuario } \\
\hline Plataformas de conocimiento & $\begin{array}{l}\text { Redes sociales de Marvel. Aplicación: Marvel Unlimited app. } \\
\text { Reseñas en páginas oficiales de entretenimiento y noticias / } \\
\text { Blogs. }\end{array}$ \\
\hline $\begin{array}{l}\text { Plataformas de opinión y } \\
\text { expresión }\end{array}$ & $\begin{array}{l}\text { Redes sociales de Marvel y cuentas creadas por los usuarios. } \\
\text { Disney's D23 / Blogs de usuarios. }\end{array}$ \\
\hline Trabajos creativos & $\begin{array}{l}\text { Imágenes y fanmade trailers, fanarts, tráiler y spots reaction, } \\
\text { mashups, parodias. Memes sobre la película (sobre todo con } \\
\text { los personajes de Captain America y Spiderman) }\end{array}$ \\
\hline Juegos interactivos & $\begin{array}{l}\text { Marvel Future Fight, Marvel Contest of Champions, Marvel } \\
\text { Puzzle Quest, Marvel Avengers Academy (referencia), Marvel } \\
\text { Avengers Alliance 2, Marvel Heroes 2016, Pinball Civil War, } \\
\text { Disney Infinity 3.0 edition, la aplicación: Marvel Unlimited app. }\end{array}$ \\
\hline
\end{tabular}




\section{Productos}

\begin{tabular}{l|l} 
Merchandising & Funko, Tsum Tsum, LEGO Marvel Super Heroes, Hasbro
\end{tabular}

Marvel Super Hero Mashers, Wallmart.

Otras actividades

Actividades diversas

Gira promocional internacional, World y Avant Premier.

Participación de los actores en tv shows: Jimmy Kimmel,

Jimmy Fallon.

Fuente: Elaboración propia.

Tras haber realizado el primer análisis presentamos las siguientes reflexiones:

1. Podemos observar que los nodos cumplen diferentes funciones y se consumen en diferentes ambientes y contextos por lo que se aprecia el valor transmedia que poseen al ser independientes y funcionar cada uno de ellos como una puerta de entrada a Civil War; pero, al mismo tiempo, mantienen una relación, por lo que el usuario solo necesita interactuar con uno para ingresar al mundo transmedial y relacionarse con el resto. Además, al ser medios tan diversos, le dan la posibilidad al público de seleccionar el que en un inicio sea de su preferencia. Así, aquellas personas que gustan de la lectura se pueden ver interesadas en un primer momento por el cómic principal; pero, posteriormente, pueden ampliar su conocimiento sobre el mundo ficcional a través de los cómics tangenciales, asistiendo a los eventos o viendo contenido en los tv shows o en las redes sociales de los productores, directores y actores.

2. En la tabla, se aprecia una cantidad de medios que han sido elaborados a lo largo de los años desde que se publicó el cómic Civil War en el 2006. Algunos han sido desarrollados simultáneamente a este, como los cómics tangenciales que refuerzan y extienden la trama; y otros, después de diez años a partir del lanzamiento de la película, como los juguetes, concursos online y Avant Premieres. Por esto, podemos deducir que el tiempo no es un limitante en la construcción del mundo transmedial: la diferencia de tiempo entre dos nodos con estructura narrativa puede ser grande, pero aun así el nodo más actual permite el acceso a otros no tan actuales. Los nodos con estructura narrativa no se ven limitados por el tiempo en el que se crearon; en cambio, los que no cuentan con este tipo de estructura es más probable que decaigan con el pasar de los años.

3. Algunos de los medios analizados como los fanarts y juguetes poseen un desarrollo narrativo interno nulo; esto no impide que lleguen al público o que sirvan de intermediario para conocer el mundo transmedial. Un ejemplo específico es el de la alianza publicitaria que realiza Marvel con Pizza Hut para promo- 
cionar la película. Se elaboraron dos diseños de cajas pizzeras con la cara de los dos personajes principales en la tapa de cada una, de esta forma incentivan al consumidor a escoger entre un personaje y el otro y, además, crean recordación de la película, sin necesidad de tener una narración interna de apoyo.

4. Ciertas unidades de análisis como el evento de Disney's D23 pueden corresponder a más de una categoría de herramienta transmedia, ya que cumplen más de una función a la vez, como brindar información extratextual, generar interacción social, motivar a que el usuario comparta este contenido a través de las redes y promover la película. Es también el caso de las actividades realizadas en los $t v$ shows, ya que dentro de nuestra clasificación pueden ser consideradas en la categoría de actividades diversas, pero al mismo tiempo pueden ser consideradas en la categoría de promociones, debido a que también cumplen una función de promoción de la película. Esto contribuye al conocimiento expansivo de la trama porque el público objetivo del tv show puede convertirse en un público potencial de la película. Asimismo, se refuerza su valor como recursos transmedia al enriquecer la vinculación y el conocimiento de la macrohistoria.

5. Las unidades de análisis guardan entre sí una relación muy estrecha: cuando se piensa en una de ellas, inevitablemente surgen referencias a otras. De esta manera, pueden no solo captar la atención del público, sino que también incentivan su curiosidad por otras al vinculárseles, ocasionando que se conozca más sobre la narrativa. Por ejemplo, los memes de la película llevan a pensar en los personajes principales y, a su vez, en los cómics; las figuras de colección de Funko están relacionadas no solo con los personajes de la película, sino también con los de los cómics. Esta relación es clave para el fortalecimiento del mundo transmedial.

6. Algunas herramientas como los cómics y videojuegos han permitido la elaboración de otros nodos como los fanarts, los perfiles y contenidos creados en las redes, inspirados en estos primeros medios. Observamos que pueden surgir herramientas transmediales que tengan como fuente de origen otras herramientas transmediales, y no necesariamente la macrohistoria. El público, al tener el poder de generar nuevo contenido (CGU), puede utilizar diferentes plataformas y redes sociales para dar a conocer su punto de vista del mundo de Civil War, ya sea sobre una escena de la película o un acontecimiento del cómic, como también sobre los tráileres o los spots televisivos. Otros ejemplos de esto son los videos en YouTube, creados por los usuarios sobre su reacción a los tráileres de la película al verlos por primera vez. Esto, al mismo tiempo, puede desencadenar videos de compilaciones de 
estas reacciones (mashup) y, a su vez, puede generar memes.

7. La mayoría de herramientas transmediales permite la participación y la interacción: el público puede involucrarse de manera directa con un nodo y al mismo tiempo compartirlo con sus amigos a través de las redes sociales. En el caso de los Live Shows, vistos por miles de personas, se realizan diferentes actividades, como la promoción de la película a través de vistazos exclusivos y entrevistas con los creadores y actores. Esto puede propiciar que los televidentes compartan fotografías, videos y contenido en redes. La página web oficial de Marvel también da la opción a los usuarios de compartir todo tipo de material, como vistazos de los cómics, curiosidades y anuncios en las redes sociales.

Siguiendo con el estudio del ecosistema mediático de Civil War, en el segundo análisis se evaluará específicamente las unidades con desarrollo narrativo para conocer qué aporte realizan a la creación y crecimiento de la estructura narrativa global del mundo transmedial. En la Tabla 3 se evaluará el nivel de profundidad, vinculación y extensión que posee cada medio en relación al cómic Civil War.

Tabla 3. Análisis del mundo transmedial en relación al cómic Civil War

\begin{tabular}{|l|c|c|c|}
\hline \multirow{2}{*}{ Nodos } & \multicolumn{3}{|c|}{ Variables } \\
\cline { 2 - 4 } & Profundidad & Vinculación & Extensión \\
\hline Cómic Civil War (nodo referencial) & 10 & 10 & 10 \\
\hline Cómic Civil War Front Line & 4 & 3 & 6 \\
\hline Cómic New Avengers & 7 & 6 & 2 \\
\hline Cómic Wolverine & 6 & 7 & 5 \\
\hline Cómic The Fantastic Four & 7 & 3 & 6 \\
\hline Cómic X-men & 7 & 4 & 6 \\
\hline Cómic Ms. Marvel & 7 & 2 & 8 \\
\hline Cómic Black Panther & 7 & 4 & 7 \\
\hline Cómic Heroes for Hire & 7 & 6 & 4 \\
\hline Cómic She-Hulk & 7 & 7 & 4 \\
\hline Cómic Thunderbolts & 4 & 2 & 5 \\
\hline Cómic Young Avengers and Runaways & 5 & 4 & 7 \\
\hline Cómic Cable and Deadpool & 6 & 3 & 6 \\
\hline Película Captain America: Civil War & 6 & 3 & 6 \\
\hline Tráiler \#1 & 5 & 4 & 5 \\
\hline Tráiler \#2 & 4 & 1 & 1 \\
\hline Comercial Audi & 4 & 2 & 1 \\
\hline Juego Marvel Future Fight & 2 & 1 & 0 \\
\hline
\end{tabular}

Fuente: Elaboración propia. 
En la Tabla 4 se analizará la profundidad, vinculación y extensión que poseen las unidades con desarrollo narra- tivo en relación a la película Captain America: Civil War.

Tabla 4. Análisis del mundo transmedial en relación a Captain America: Civil War

\begin{tabular}{|l|c|c|c|}
\hline \multirow{2}{*}{ Nodos } & \multicolumn{3}{|c|}{ Variables } \\
\cline { 2 - 4 } $\begin{array}{l}\text { Película Captain America: Civil War } \\
\text { (nodo referencial) }\end{array}$ & Profundidad & Vinculación & Extensión \\
\hline Cómic Civil War & 10 & 10 & 10 \\
\hline Cómic Civil War Front Line & 8 & 4 & 8 \\
\hline Cómic New Avengers & 6 & 1 & 6 \\
\hline Cómic The Amazing Spiderman & 5 & 1 & 6 \\
\hline Cómic Wolverine & 7 & 1 & 7 \\
\hline Cómic The Fantastic Four & 5 & 0 & 7 \\
\hline Cómic X-men & 6 & 0 & 5 \\
\hline Cómic Ms. Marvel & 6 & 0 & 6 \\
\hline Cómic Black Panther & 5 & 0 & 5 \\
\hline Cómic Heroes for Hire & 5 & 3 & 5 \\
\hline Cómic She-Hulk & 6 & 0 & 7 \\
\hline Cómic Thunderbolts & 4 & 0 & 2 \\
\hline Cómic Young Avengers and Runaways & 4 & 0 & 4 \\
\hline Cómic Cable and Deadpool & 4 & 0 & 3 \\
\hline Tráiler \#1 & 7 & 0 & 4 \\
\hline Tráiler \#2 & 8 & 6 & 0 \\
\hline Comercial Audi & 5 & 7 & 0 \\
\hline Juego Marvel Future Fight & 7 & 3 & 2 \\
\hline
\end{tabular}

Fuente: Elaboración propia.

Tras haber realizado el segundo análisis, se encontró:

1. Fue necesario delimitar dos nodos principales, debido a que, si bien el cómic es el nodo inicial del mundo narrativo de Civil War, la película, aunque es un nodo nacido a raíz de esta, ha permitido el desarrollo de muchos productos transmediales. No obstante, al cruzar ambos análisis, teniendo como nodos principales al cómic y a la película, se puede obtener una sola panorámica del mundo transmedial de Civil War. Esto nos lleva a plantear que la macrohistoria no se corresponde perfectamente con un solo nodo, sino que forma parte de la construcción del mundo transmedial como una unidad fundamentada por las relaciones y la participación del público.

2. Dentro de cada variable del análisis, se realizó la evaluación de tres cate- 
gorías: personajes, conflictos y subtramas. El elemento personajes es el punto que mayor conexión genera pues se aprecia en los cómics, la película, los tráileres, las alianzas publicitarias y los videojuegos. Si bien la película tiene alteraciones por ser una adaptación de la trama principal, el elemento personaje permite y mantiene la vinculación entre ambos nodos principales. Es el punto de referencia que los productores utilizan para generar mayor vinculación con el público, el cual puede sentirse identificado con sus personajes favoritos. De aquí la importancia de crear personajes con potencial para atraer y generar afinidad con las personas.

3. Podemos observar que los nodos secundarios guardan un mayor nivel de vinculación con los nodos principales en relación a los que fueron creados. Los cómics tangenciales tienen una mayor vinculación con el cómic principal que con la película, dado que dichas narraciones han sido creadas en torno a la trama central, brindando información suplementaria a la historia. Del mismo modo, en el caso de la película, los tráileres están más vinculados, pues son pequeños vistazos de lo que sucede en el largometraje.

4. En cuanto a la extensión narrativa de los nodos, podemos ver que los cómics tangenciales y el juego realizan un mayor aporte tanto a la trama del cómic principal como a la de la película, pues cuentan con un mayor desarrollo de personajes, conflictos y subtramas nuevos; a diferencia de los tráileres y el comercial de Audi, cuyo aporte al desarrollo narrativo principal es prácticamente nulo pues su contenido se limita a lo mostrado en la película. Como ya hemos mencionado antes, la película es una adaptación y muestra solo algunos de los personajes del cómic principal, pero no desarrolla nuevos; como tampoco desarrolla nuevos conflictos y subtramas.

\section{Conclusiones}

Una narrativa transmedia puede ser adaptada a una variedad de medios y plataformas para darse a conocer y captar el interés del público; sin embargo, no es necesario que todos estos medios posean un desarrollo narrativo para brindar un aporte y acrecentar el mundo transmedial del cual forman parte. Este es el caso de los juguetes de Civil War o alguna de las alianzas publicitarias, que no cuentan con un relato que contribuya a la trama principal, pero sí tienen una vinculación con el mundo transmedial.

Los mundos transmediales estarán más enriquecidos en función a la diversidad de medios que lo conformen, esto es porque cada nodo, al ser independiente, puede ser considerado una puerta al universo transmedia y brinda un aporte al conjunto. Además, el espectador puede elegir entre esta variedad y sentirse más a gusto con uno o varios de ellos. Entendemos entonces como una posibilidad que, a menor cantidad de medios, menores sean las 
puertas de entrada para el público y, probablemente, menores las posibilidades de que se identifique y conozca el mundo.

La pluralidad de elementos narrativos contribuye no solo a que el universo llegue a diversos públicos, sino a que se dé paso a una retroalimentación con ellos. Así, el usuario puede sentirse identificado con los personajes y conflictos de la trama, que puede conocer más a través de diferentes elementos como cómics, películas, adelantos, contenido textual y visual presentado en diferentes plataformas y dispositivos. Asimismo, el público puede compartir toda esta información a través de las redes sociales, que le permiten crear incluso más contenido.

El mundo transmedial de Civil War puede ser considerado uno de los más completos por la gran cantidad y calidad de elementos transmediales que lo integran, y uno de los más complejos por la profundidad, vinculación y extensión de su desarrollo narrativo.

Para finalizar, podemos decir que en este estudio se brinda como aporte científico dos importantes herramientas metodológicas para el diseño y planificación de mundos transmediales: la primera, basada en un estudio de los medios como herramientas transmediales, nos permite tener una vista panorámica del ecosistema mediático, así como también puede ser utilizada como una guía para la elaboración de herramientas potenciales en un mundo transmedial. Con esto, la expansión se puede dar de una forma más acertada, además de atraer y crear una vinculación con el público para generar feedback constructivo.

La segunda herramienta es la que evalúa la estructura narrativa del mundo transmedial, teniendo como variables fundamentales de cada relato la profundidad, vinculación y extensión con las que se ha desarrollado; y subcategorías como personajes, conflictos y subtramas, que ayudarán a que se explore los alcances narrativos de cada historia.

Todo esto generará contacto, interés y vinculación con el público; además, contribuirá a que el producto transmedia sea más completo y complejo por su diversidad de medios potenciales y su buen desarrollo narrativo. La clave es que una buena narrativa transmedia tenderá a construir un mundo transmedial con diversos nodos que sirvan como puerta de entrada y que refuercen el disfrute por parte del espectador. El mundo transmedial propiciará una especial vinculación del público con la historia, al encontrar variedad de medios y plataformas en las que puede explorarla, así como diferentes niveles de profundidad, vinculación y expansión.

\section{Bibliografía}

Askwith, I. D. (2007). Television 2.0: Reconceptualizing TV as an engagement medium. Tesis de Master of Science in Comparative Media Studies. Cambridge: Massachusetts Institute of Technology. Recuperado de http://cmsw.mit.edu/television-2-0-tv-as-an-engagement-medium/ 
Bellón, T. (2012). Nuevos modelos narrativos. Ficción televisiva y transmediación. Comunicación: Revista Internacional de Comunicación Audiovisual, Publicidad y Estudios Culturales, (10), 17-31.

Belsunces, A. (2011). Producción, consumo y prácticas culturales en torno a los nuevos media en la cultura de la convergencia: el caso de Fringe como narración transmedia y lúdica. Tesis de Máster en Sociedad de la Información y el Conocimiento. Barcelona: Universitat Oberta de Catalunya.

Carlón, M. (2015). La concepción evolutiva en el desarrollo de la ecología de los medios y en la teoría de la mediatización: ¿la hora de una teoría general? Palabra Clave, 18(4), 1111 1136. doi: 10.5294/pacla.2015.18.4.7

Corona Rodríguez, J. M. (2016). ¿Cuándo es transmedia?: discusiones sobre lo transmedia(l) de las narrativas. Revista ICONO14. Revista científica de Comunicación y Tecnologías emergentes, 14(1), 30-48. doi: 10.7195/ri14.v14i1.919

Dena, C. (2009). Transmedia Practice: Theorising the Practice of Expressing a Fictional World across Distinct Media and Environments. Tesis doctoral. Sydney: University of Sydney.

Fernández Castrillo, C. (2013). Prácticas transmedia en la era del prosumidor: Hacia una definición del Contenido Generado por el Usuario (CGU). CIC Cuadernos de Información y Comunicación, 19, 53-67. Recuperado de http://revistas.ucm.es/index.php/CIYC/article/ view/43903/41501

Jenkins, H. (2003). Transmedia storytelling: Moving characters from books to films to video games can make them stronger and more compelling. MIT Technology Review. Recuperado de: https://www.technologyreview.com/s/401760/transmedia-storytelling/

Jenkins, H. (2006). Convergence culture: Where old and new media collide. New York: NYU Press. Jenkins, H. (2007). Transmedia storytelling 101. Confessions of an Aca-Fan. Recuperado de http://henryjenkins.org/2007/03/transmedia_storytelling_101.html

Jenkins, H. (2010). Transmedia storytelling and entertainment: An annotated syllabus. Continuum: Journal of Media \& Cultural Studies, 24(6), 943-958. doi: 10.1080/10304312.2010.510599

Jenkins, H., Ford, S. \& Green, J. (2015). Cultura Transmedia: la creación de contenido y valor en una cultura de red. Barcelona: GEDISA.

Kinder, M. (1991). Playing with power in movies, television, and video games: From Muppet babies to teenage mutant Ninja Turtles. Berkeley. Los Angeles: University of California Press.

Klastrup, L. \& Tosca, S. (2004). Transmedial Worlds-rethinking cyberworld design. Proceedings International Conference on Cyberworlds, 409-416. Los Alamitos: IEEE Computer Society.

Klastrup, L., \& Tosca, S. (2014). Game of Thrones: Transmedial Worlds, Fandom, and Social Gaming. En Ryan, M. L. \& Thon, J. N. (eds.). Storyworlds Across Media (pp. 295-314). Lincoln: University of Nebraska Press.

Lastra, A. (2016). El poder del prosumidor. Identificación de sus necesidades y repercusión en la producción audiovisual transmedia. Revista ICONO14. Revista científica de Comunicación y Tecnologías emergentes, 14(1), 71-94. doi: 10.7195/ri14.v14i1.902 
Orozco, G. (2006). Comunicación social y cambio tecnológico: un escenario de múltiples desordenamientos. En Comunicación, universidad y sociedad del conocimiento: actas del IV Congreso Internacional (pp. 149-164). Servicio de Publicaciones.

Postman, N. (2000). The Humanism of Media Ecology. Proceedings of the Media Ecology Association, 1, 10-27. Recuperado de http://w.media-ecology.org/publications/MEA_proceedings/v1/postman01.pdf

Renó, D., \& Flores, J. (2012). Periodismo transmedia. Madrid: Fragua.

Robledo, K., Atarama, T. \& Palomino, H. (2017). De la comunicación multimedia a la comunicación transmedia: una revisión teórica sobre las actuales narrativas periodísticas. Estudios sobre el Mensaje Periodístico, 23(1), 223-240. doi:10.5209/ESMP.55593

Rodríguez, R. (2012). Sangre fresca publicitaria: True Blood y las transfusiones de la ficción. Anàlisi: quaderns de comunicació i cultura, 65-80.

Rodríguez, R., Ortíz, F., \& Sáez V. (2014). Contenidos transmedia de las teleseries españolas: clasificación, análisis y panorama en 2013. Comunication E Society, 27(4), 73-94. doi: 10.15581/003.27.4.sp.73-94

Rosendo, N. (2016). Mundos transmediales: revisión conceptual y perspectivas teóricas del arte de crear mundos. Revista ICONO14. Revista científica de Comunicación y Tecnologías emergentes, 14(1), 49-70. doi: 10.7195/ri14.v14i1.930

Ryan, M. L. (2014). Story/Worlds/Media. Tuning the Instruments of a MediaConscious Narratology. En M. L. Ryan \& J. N. Thon (eds.). Storyworlds across Media. Toward a MediaConscious Narratology (pp. 25-49). Lincoln: University of Nebraska Press.

Scolari, C. A. (2009). Transmedia storytelling: Implicit consumers, narrative worlds and branding in contemporary media production. International Journal of Communication, 3 , 586-606.

Scolari, C. (2011). Narrativas transmediáticas y adaptaciones: el caso Tintin. Recuperado de https:// hipermediaciones.com/2011/11/10/narrativa-transmediatica-y-adaptaciones-el-caso-tintin/

Scolari, C. (2013). Narrativa transmedia: cuando todos los medios cuentan. Barcelona: Deusto.

Scolari, C. (2014). Don Quixote of La Mancha: Transmedia storytelling in the Grey Zone. International Journal of Communication, 8, 2382-2405.

Scolari, C., Jiménez, M. \& Guerrero, M. (2012). Narrativas transmediáticas en España: cuatro ficciones en busca de un destino cross-media. Comunicación y Sociedad, 25(1), 137-163.

Scolari, C., Aguado, J. \& Feijóo, C. (2013). Una ecología del medio móvil: contenidos y aplicaciones. En J. Aguado, C. Feijóo, \& I. Martínez (coords.). La comunicación móvil: Hacia un nuevo ecosistema digital (pp. 79-106). Barcelona: Gedisa.

Tur-Viñes, V., \& Rodríguez Ferrándiz, R. (2014). Transmedialidad, Series de Ficción y Redes Sociales: El Caso de Pulseras Rojas en el Grupo Oficial de Facebook (Antena 3. España). Cuadernos.info, (34), 115-131.

Wolf, M. J. (2012). Building Imaginary Worlds: The Theory and History of Subcreation. New York: Routledge.

Zimmermann, A. (2015). Blurring the Line Between Fiction and Reality. Functional Transmedia Storytelling in the German TV Series About: Kate. Image, 22, 22-35. 